RASĀYAN J. Chem.

Vol. 14 | No. 2 |778-784| April - June | 2021

ISSN: 0974-1496 | e-ISSN: 0976-0083 | CODEN: RJCABP

http://www.rasayanjournal.com

http://www.rasayanjournal.co.in

\title{
BITUMEN AND ASPHALT CONCRETE QUALITATIVE PROPERTIES IMPROVEMENT DEPENDING ON RUBBER CRUMB USING
}

\author{
K.K. Syrmanova ${ }^{1,2, \bowtie}$, Z. K. Alipbekova ${ }^{1}$, U.S. Suleimenov ${ }^{1}$, Z.B. \\ Kaldybekova $^{1}$, A.Y. Kovaleva ${ }^{1}$ and Y.T. Botashev ${ }^{1}$ \\ ${ }^{1}$ Oil Processing and Petrochemistry Department, Auezov South Kazakhstan State University, \\ 160012, Shymkent, Kazakhstan \\ ${ }^{2}$ Chemistry Department, Miras University, 160000, Shymkent, Kazakhstan \\ Corresponding Author: syrmanova.kulash@mail.ru
}

\begin{abstract}
In the article bitumen and asphalt concrete qualitative properties depending on using rubber, the crumb is considered. Bituminous binders' comparative physical and mechanical characteristics containing modified crumb are given. It is proved that the increase in the quantity of Kulantau vermiculite leads to a decrease in the thickness of bitumen films on the particle surface. The modification by rubber crumb allows to increase the quality of the bitumen binder, durability of the coatings and to reduce the cost of asphalt coatings, as well as to utilize largetonnage rubber products waste.

Keywords: Polymer-bitumen Compositions, Rubber Crumb Modification, Utilization, Vermiculite, Structure, Elasticity, Strength
\end{abstract}

RASĀYAN J. Chem., Vol. 14, No.2, 2021

\section{INTRODUCTION}

Oil bitumen and asphalt concrete quality improvement are one of the current problems in the road industry of many countries.

The quality of oil bitumen mainly determines the quality and using duration of asphalt pavements, since all the basic properties of asphalt concrete as a thermoplastic material are determined by the properties of oil bitumen. ${ }^{1-3}$

One of the main methods of improving the quality and durability of asphalt concrete coatings is bitumen modification by polymer materials. The development of polymer-bitumen materials is the most perspective way to create high-quality road surfaces, sealants, waterproofing, soft corvels, etc. Usually, road bitumen is characterized by a plasticity interval no higher than $60-65^{\circ} \mathrm{C}$. It is not enough for the upper layers of pavements in the climatic conditions of most regions.

Also, viscous road bitumen practically has not enough elastic properties, which is determined by the stability to destruction under the influence of cyclic loading of composite materials. Therefore, bituminous binders fundamentally require modification and improvement of physical-mechanical properties since their initial properties cannot provide the necessary durability of asphalt concrete pavements in the conditions of increasing traffic congestion.

A significant amount of old car tires used for the regeneration and the perspective of rubber grinding capacities development create the prerequisites for the widespread use of vulcanized crushed rubber in road construction to improve the running abilities of asphalt concrete pavements.

All these factors indicate the necessity to create a new large-capacity bitumen production in the Republic of Kazakhstan, which both create bitumen materials with improved running abilities and solve the problems of recycling worn tire.

Various methods for bitumen modification are known. Comparative research of bitumen modification various methods effectiveness proved that using of rubber crumb additives is a perspective direction in the bitumen modification. The advantages of using rubber as a bitumen modifier are the following ${ }^{4-5}$ : 
- Low cost of modifier, due to the cost of rubber crumb is in 5 to 10 times lower than the cost of rubbers and polymer additives;

- High quality of the obtained modified bitumen, no worse than the quality of bitumen modified with synthetic rubber.

- Environmental feasibility of worn-out tires and other waste rubber products utilization.

Rubber crumb is obtained by processing worn-out tires and other rubber waste products. Car tires are the most abundant resource of worn rubber. Their utilization is a serious environmental problem in many countries $^{6}$.

The possibility of using rubber crumb to modify bitumen and asphalt concrete has been known for a long time and is developing in two ways ${ }^{1-5}$ :

1. "Dry" technology involves rubber crumb addition to the mineral material before adding it to bitumen. The amount of crumb rubber (particles smaller than $1 \mathrm{~mm}$ ) should be $1.5-3 \%$ by weight of mineral materials. However, rubber crumb using as an asphalt concrete filler allows not to lose the valuable properties of the rubber, which is part of the rubbers.

2. "Wet" technology is more effective as rubber transferring to a soluble state in the medium of bitumen or tar. Rubber-bitumen binders and chemically modified with rubber crumb bitumen are obtained on this technology.

The traditional technology of a homogeneous rubber-bitumen binder producing involves mechanical mixing of rubber crumb (from 5 to $30 \%$ by weight) with bitumen (tar, deasphalting asphalt or mixtures thereof) at temperatures of $150-250^{\circ} \mathrm{C}$ for a certain time (from 30 minutes to 24 hours) in the presence of polymeric active substances or plasticizers. Petroleum tars, heavy extracts of the selective purification of oil fractions, shale oil, coal-heavy oils, etc. are used as plasticizers..$^{1-3}$ The most important factors determining the quality of a rubber-bitumen binder are temperature and the duration of obtaining a rubber-bitumen binder; chemical, the fractional composition of rubber crumb; grade, group chemical composition and content of bitumen in a binder; type of plasticizer; stay rubber-bitumen binder at process temperatures after obtainment; surface condition of rubber crumb. Rubber is crushed using roll, elastic deformation and grinding methods at liquid nitrogen temperatures. ${ }^{7}$

The technological parameters of the process of rubber-bitumen binder production depend on the type of rubber that is part of the rubber crumb and the type of plasticizer. Upon receipt of a rubber-bitumen binder, the processes of swelling and plasticization of rubber, as well as the destruction of the spatial structure of rubber, simultaneously occur, while the bonds with the soot filler and in the rubbers, themselves are destroyed.

The temperature of various rubbers' destruction is not the same. For example, chamber rubbers have the destruction temperature is $93^{\circ} \mathrm{C}$, in tread rubber $-208^{\circ} \mathrm{C}$, and in diaphragm rubber $-230^{\circ} \mathrm{C}$

Improving the quality of the rubber-bitumen binder will be achieved in the case when the rubber crumb is plasticized with a minimum degree of destruction. If the plasticization of rubber crumb is carried out due to tar and high molecular weight aromatic hydrocarbons of bitumen, noticeable improvement in the lowtemperature properties of the rubber-bitumen binder will not observe, since these hydrocarbons are vitrified at high temperatures. During rubber crumb plasticizing by paraffin-naphthenic hydrocarbons, it is possible to improve the low-temperature properties of a rubber-bitumen binder. However, tread and diaphragm rubbers have a greater chemical affinity for aromatic hydrocarbons.

The rubber-bitumen binder properties also depend on the surface condition of the rubber crumb. During rubber grinding at liquid nitrogen temperatures, rubber particles have a completely smooth surface, which affects the speed of its swelling and plasticization in the components of bitumen. The rubber crumb, crushed by the elastic deformation method, has a looser particle surface structure, which contributes to its faster swelling in the bitumen components.

\section{EXPERIMENTAL}

Oil road bitumen marked 70/100 was researched and used as an object of research. Bitumen 70/100 is a large-capacity oil refining product, has a lot of valuable technical properties and is widely used in road construction. Bitumen was taken from Shymkent bitumen plant of LLP "Gazpromneft-Bitumen Kazakhstan". The plant's capacity is 500 tons of bitumen per day. The stocks for the production of 
RASĀYAN J. Chem.

Vol. 14 | No. 2 |778-784| April - June | 2021 bitumen is tar (heavy oil residue of vacuum distillation) delivered from the Omsk Oil Refinery LLP "Gazpromneft-Omsk Oil Refinery".

Rubber crumb for the research was taken from LLP "ECO-Tire".

The physical and mechanical properties of bitumen and bitumen compositions were researched according to the standard methods. ${ }^{8}$ IR spectroscopic studies were carried out on a Shimadzu IR Prestige-21 IR Fourier spectrometer with a prefabricated impaired total internal reflection by company Pike Technologies. In this case, the IR spectra of bitumen samples were obtained without and with different contents of rubber crumb $(2 \%-25 \%){ }^{9}$

Vermiculite deposits of the Turkestan region have significant differences in mineralogical composition. For research Kulantau vermiculite was used. A photograph of samples of expanded Kulantau vermiculite is shown in Fig.-1.

Microscopic research and the results of X-ray diffraction analysis of vermiculite samples of the Kulantau deposit proved that the main component is cochubeite $-(\mathrm{Mg}, \mathrm{Fe}, \mathrm{Al})_{6}(\mathrm{Si}, \mathrm{Cr})_{4} \mathrm{O}_{10}(\mathrm{OH})_{8}$, the product of the change in biotite with a low content of $\mathrm{K}_{2} \mathrm{O}$ and a high content of $\mathrm{H}_{2} \mathrm{O}$, presented flakes of brown mica. The impurities are observed: calcite, crystals of chlorite, quartz. ${ }^{10-11}$

Expanded vermiculite, depending on the size and particles, is divided into several fractions, the bulk density of which, depending on the swelling of the raw material, can fluctuate over a wide range. The low bulk density of expanded vermiculite is far from its only advantage. Vermiculite particles have elasticity. Expanded vermiculite has elasticity, which is expressed in the partial restoration of the height of the precompressed sample after removing the load from it. The total deformation of expanded vermiculite during axial compression due to the air trapped between the plates is composed of elastic and residual. Expanded vermiculite is characterized by anisotropic properties: in the direction perpendicular to the cleavage plane, vermiculite grains have less strength than in the direction parallel to the cleavage plane. Accordingly, the first determines the deformative properties, and the second - the fragility of expanded vermiculite. The following crystal-chemical formulas have been proposed for vermiculites. ${ }^{11}$

Vermiculite has the following formulas: according to Bershard - $(\mathrm{H} 2 \mathrm{O})_{\mathrm{x}}(\mathrm{Mg}, \mathrm{Ca})_{\mathrm{y}}(\mathrm{Al}, \mathrm{Fe}, \mathrm{Mg})(\mathrm{Si}, \mathrm{Al}$, $\mathrm{Fe})_{4} \mathrm{O}_{10}(\mathrm{OH})_{\mathrm{z}}$ where y - varies from 0.22 to $0.36 \mathrm{z}-3$ and according to Grüner - $22 \mathrm{MgO} \cdot 5 \mathrm{Al}_{2} \mathrm{O}_{3}$. $\mathrm{Fe}_{2} \mathrm{O}_{3} \cdot 22 \mathrm{SiO}_{2} \cdot 4 \mathrm{H}_{2} \mathrm{O}$.Expanded vermiculite is shown in Fig.-1.

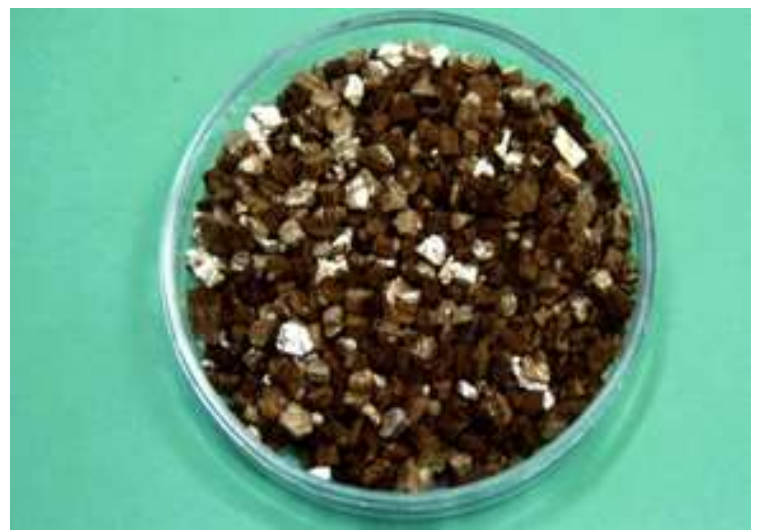

Fig.-1: Expanded Vermiculite (Kulantau)

The structure of vermiculite is given below in Fig.-2 with octahedral, tetrahedral and hydrated interlayer cations, which are replaced by magnesium when the complete formation of vermiculite occurs. The degree of hydration and the type of interlayer cations have a significant effect on its physical and chemical properties, and, therefore, affect its characteristics and application. ${ }^{10-11}$

The results of the study of the qualitative characteristics of vermiculite of the Kulantau field are given in Tables- 1 and 2.

The result was an increase in the durability of the bitumen-rubber binder with improved rheological characteristics, a significant reduction in cost due to an increase in the life of the road asphalt pavement.

Table- 3 shows the composition of bitumen binders containing modified crumb. 
RASĀYAN J. Chem.

Vol. 14 | No. 2 |778-784| April - June | 2021

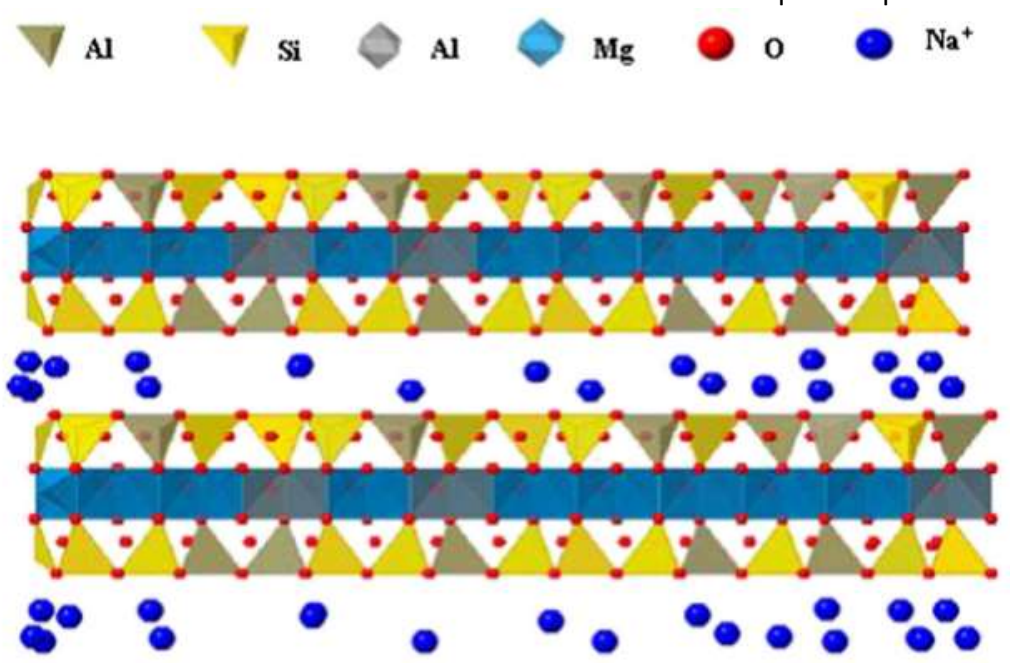

Fig.-2: Schematic Representation of the Vermiculite Structure

Table-1: The Chemical Composition of Vermiculite Deposits of the Turkestan Region

\begin{tabular}{c|c|c|c}
\hline \multirow{2}{*}{ Compounds, \% } & \multicolumn{2}{|c}{ Vermiculite } & Kulantau \\
\cline { 2 - 4 } & Iirsu & Zhelandy & - \\
\hline $\mathrm{K}_{2} \mathrm{O}$ & $7,5-10,4$ & $5,8-11,5$ & $15,5-22,8$ \\
\hline $\mathrm{MgO}$ & $6,8-11,6$ & $0,4-27,4$ & $10,2-12,8$ \\
\hline $\mathrm{Al}_{2} \mathrm{O}_{3}$ & $10,2-16,3$ & $9,5-30,6$ & $37,1-41,5$ \\
\hline $\mathrm{SiO}_{2}$ & $38,5-44,4$ & $32,7-44,1$ & $6,4-17,2$ \\
\hline $\mathrm{Fe}_{2} \mathrm{O}_{3}$ & $0,01-0,03$ & $0,14-21,2$ & $8,3-17,5$ \\
\hline $\mathrm{H}_{2} \mathrm{O}$ & $0,6-5,5$ & $0,85-4,4$ & $1,4-2,8$ \\
\hline $\mathrm{FeO}$ & - & $2,4-30,0$ & \\
\hline
\end{tabular}

Table-2: Qualitative Characteristics of Vermiculite of the KulantauDeposit

\begin{tabular}{c|c|c|c|c}
\hline Sample No. & Humidity, $\%$ & Degree of Hydration, $\%$ & Volumetric weight, $\mathrm{kg} / \mathrm{m}^{3}$ & Vermiculite Content, $\%$ \\
\hline 1. & 6,2 & 65 & 178 & 30 \\
\hline 2. & 9,0 & 70 & 200 & 35 \\
\hline 3. & 3,7 & 60 & 130 & 28 \\
\hline 4. & 3,1 & 75 & 140 & 26 \\
\hline
\end{tabular}

Table-3: Composition of Bituminous Binders Containing Modified Crumb

\begin{tabular}{c|c|c|c}
\hline S. No. & $\begin{array}{c}\text { Bitumen Quantity, } \% \\
\text { Mass }\end{array}$ & $\begin{array}{c}\text { The Amount of Rubber Crumb, } \\
\text { \%, Mass }\end{array}$ & $\begin{array}{c}\text { The Amount of expanded Kulantau } \\
\text { Vermiculite, \%Mass }\end{array}$ \\
\hline 1. & 100 & - & - \\
\hline 2. & 93 & 5 & 2 \\
\hline 3. & 86 & 10 & 4 \\
\hline 4. & 79 & 15 & 6 \\
\hline 5. & 72 & 20 & 10 \\
\hline 6. & 65 & 25 & \\
\hline
\end{tabular}

Bitumen 70/100 samples were taken from the obtained bitumen binders.

Figures-3shows the IR spectrum of the structures of the original bitumen 70/100 bitumen without the addition of rubber crumb (Fig.-3), with the addition of different amounts of rubber crumb (5\%, 10\%, Fig.-5 to 7) and the combined IR spectra of bitumen compositions containing different amounts of crumb rubber (2\%-25\%). Device: Shimadzu IR Prestige-21 IR Fourier spectrometer with Pike Technologies Miracle prefix of distorted total internal reflection. 
RASĀYAN J. Chem.

Vol. 14 | No. 2 |778-784| April - June | 2021

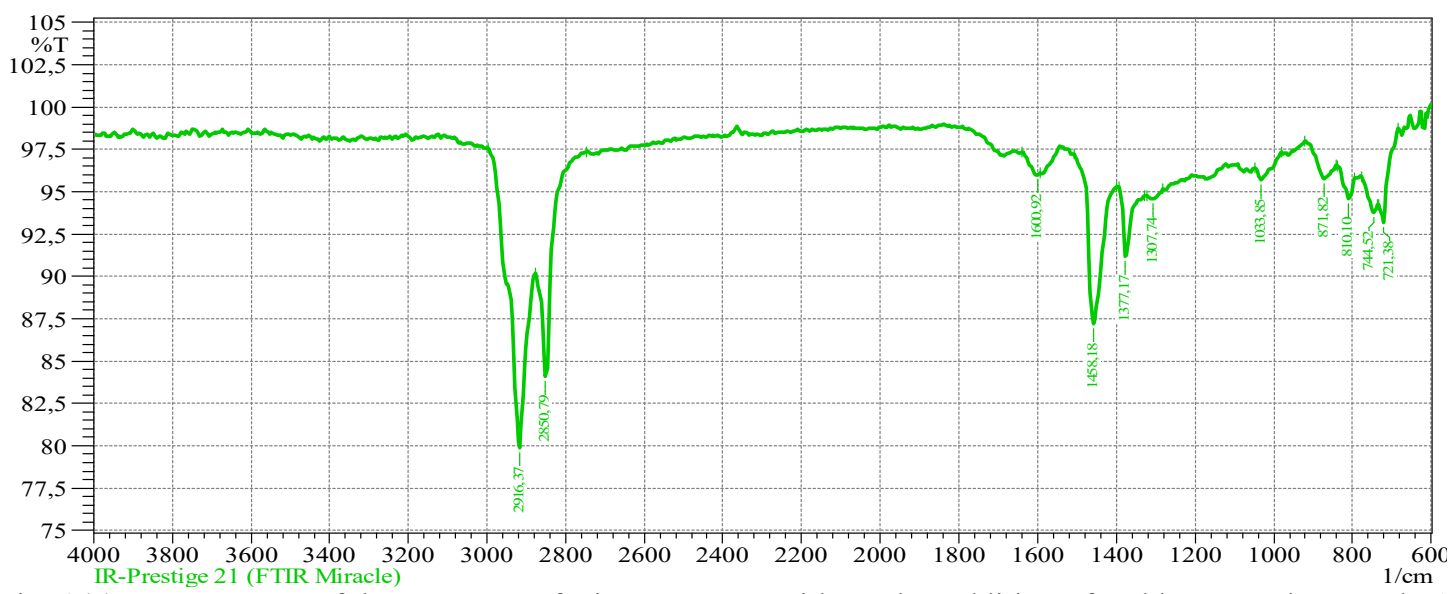

Fig.-3(a): IR Spectrum of the Structure of Bitumen BND without the Addition of Rubber Crumb, Sample-1

\begin{tabular}{|l|l|l|l|l|l|l|l|}
\hline No. & Peak & Intensity & $\begin{array}{c}\text { Corr. } \\
\text { Intensity }\end{array}$ & Base (H) & Base (L) & Area & Corr. Area \\
\hline 1 & 721,38 & 93,177 & 2,080 & 732,95 & 682,80 & 0,845 & 0,113 \\
\hline 2 & 744,52 & 93,762 & 0,823 & 775,38 & 736,81 & 0,949 & 0,088 \\
\hline 3 & 810,10 & 94,612 & 1,445 & 837,11 & 794,67 & 0,872 & 0,143 \\
\hline 4 & 871,82 & 95,783 & 1,347 & 921,97 & 840,96 & 1,181 & 0,217 \\
\hline 5 & 1033,85 & 95,709 & 0,904 & 1049,28 & 979,84 & 1,112 & 0,153 \\
\hline 6 & 1307,74 & 94,564 & 0,343 & 1323,17 & 1280,73 & 0,991 & 0,041 \\
\hline 7 & 1377,17 & 91,161 & 4,000 & 1392,61 & 1327,03 & 1,861 & 0,405 \\
\hline 8 & 1458,18 & 87,199 & 9,117 & 1508,33 & 1400,32 & 3,413 & 1,598 \\
\hline 9 & 1600,92 & 95,967 & 0,337 & 1639,49 & 1593,20 & 0,710 & 0,037 \\
\hline 10 & 2850,79 & 84,078 & 7,564 & 2877,79 & 2746,63 & 3,873 & 0,731 \\
\hline 11 & 2916,37 & 79,907 & 12,264 & 2997,38 & 2881,65 & 5,921 & 2,556 \\
\hline
\end{tabular}

Fig.-3(b): Screen of Peak Table from the Device Shimadzu IR Prestige-21 IR Fourier Spectrometer, Sample 2(5\%)

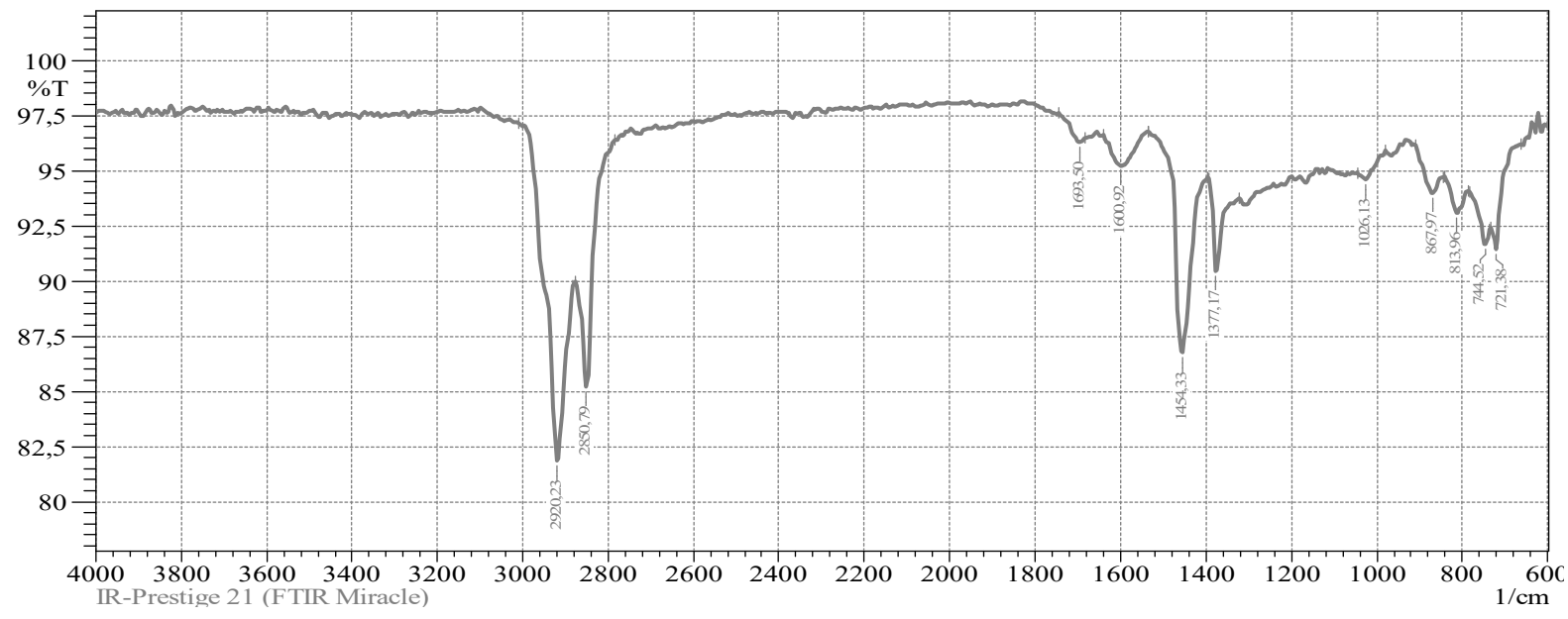

Fig.-4(a): IR Spectrum of Bitumen without and with the Addition of 5\% Rubber Crumb

IR spectra allowed to find that during the modification process there is a significant change in the peaks in the region of $700-750 \mathrm{~cm}^{-1}, 1380-1490 \mathrm{~cm}^{-1}$ and $2440-2920 \mathrm{~cm}^{-1}$ of the resulting mixtures. This proves the formation of structural compounds in the dispersion medium of the obtained compositions modified with rubber crumb. At temperatures above $230{ }^{\circ} \mathrm{C}$ in the Republic of Kazakhstan introduced into bitumen, destructive processes predominate, depending on the duration and temperature, can lead to the destruction 
RASĀYAN J. Chem.

Vol. 14 | No. 2 |778-784| April - June | 2021 of the rubber. In this case, low-boiling hydrocarbons with a boiling point of $150-350{ }^{\circ} \mathrm{C}$ are formed. Physical-mechanical characteristics of bitumen binders containing modified chips are given in Table-4.

\begin{tabular}{|l|l|l|l|l|l|l|l|}
\hline No. & Peak & Intensity & $\begin{array}{c}\text { Corr. } \\
\text { Intensity }\end{array}$ & Base (H) & Base (L) & Area & Corr. Area \\
\hline 1 & 721,38 & 91,440 & 1,631 & 732,95 & 663,51 & 1,679 & 0,089 \\
\hline 2 & 744,52 & 91,696 & 0,943 & 783,10 & 736,81 & 1,509 & 0,081 \\
\hline 3 & 813,96 & 93,099 & 1,312 & 840,96 & 786,96 & 1,516 & 0,161 \\
\hline 4 & 867,97 & 93,970 & 1,260 & 910,40 & 844,82 & 1,546 & 0,204 \\
\hline 5 & 1026,13 & 94,602 & 0,582 & 1045,42 & 979,84 & 1,414 & 0,081 \\
\hline 6 & 1377,17 & 90,437 & 3,995 & 1392,61 & 1323,17 & 2,244 & 0,429 \\
\hline 7 & 1454,33 & 86,782 & 8,797 & 1535,34 & 1396,46 & 4,261 & 1,622 \\
\hline 8 & 1600,92 & 95,205 & 1,482 & 1639,49 & 1535,34 & 1,885 & 0,372 \\
\hline 9 & 1693,50 & 96,304 & 0,416 & 1743,65 & 1681,93 & 0,858 & 0,059 \\
\hline 10 & 2850,79 & 85,230 & 6,627 & 2877,79 & 2785,21 & 3,441 & 0,737 \\
\hline 11 & 2920,23 & 81,841 & 10,195 & 3008,95 & 2881,65 & 5,885 & 2,134 \\
\hline
\end{tabular}

Fig.-4(b): Screen of Peak Table from the Device Shimadzu IR Prestige-21 IR Fourier Spectrometer

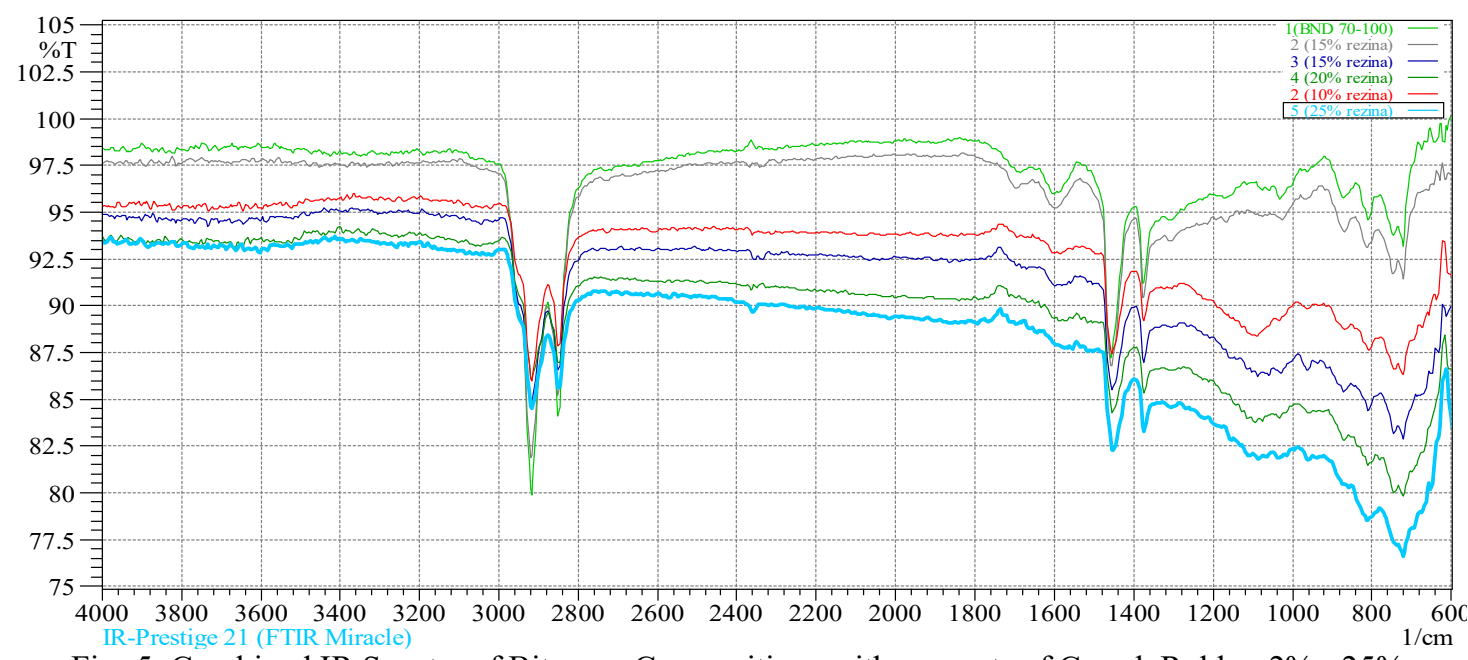

Fig.-5: Combined IR Spectra of Bitumen Compositions with amounts of Crumb Rubber 2\% - 25\%

In comparison with the known similar bituminous binders, the claimed one containing modified rubber crumb is distinguished by increased environmental and energy-saving parameters while reducing transportation costs. Modification of rubber crumb is achieved through the addition of Kulantau vermiculite.

The quality of the structure of asphalt concrete depends on many factors, but it is obvious that it is largely determined by the quality of the binder in thin films formed under the influence of the grain surface of mineral components. Resistance potential of the material structure to operational influences depends on the interaction activity at the "bitumen - rubber crumb" phase boundary, since bitumen is structured on the crumb surface, the intensity of which is determined by the contact surface area and the adsorption capacity of the mineral component.

Bitumen is a complex with a mineral filler that provides an increase in the density of the composition, an increase in the coefficient of internal friction, an increase in resistance to shock loads, compressive strength and a decrease in brittleness. The characteristics of rubber crumb, also affecting the intensity and nature of the interaction at the "bitumen-rubber crumb" interface-the size and shape of the particles, surface texture and porosity-are also of great importance. It is known that bitumen, following the micellar 
RASĀYAN J. Chem.

Vol. 14 | No. 2 |778-784| April - June | 2021 theory, is a colloidal system in an oil medium in which asphaltenes are surrounded by a shell of resins. Thus, the most chemically active functional groups that are part of tar-asphaltene complexes are blocked by a chemically inert oil shell. ${ }^{1-2}$

As a result of the interaction of bitumen with a material having a high specific surface and a finely porous structure, the group composition of bitumen changes due to the selective diffusion of oils and resins into the material, which leads to a change in the properties of bitumen layers on the particle surface and the formation of strong bitumen films on the grain surface.

Table-4: Comparative Physical and Mechanical Characteristics of Bituminous Binders Containing Modified Crumb

\begin{tabular}{|c|c|c|c|c|c|c|c|c|c|}
\hline \multirow[t]{2}{*}{ S. No. } & \multirow[t]{2}{*}{ Indicators } & \multicolumn{7}{|c|}{ Suggested Composition } & \multirow[t]{2}{*}{ Prototype } \\
\hline & & 1 & 2 & 3 & 4 & 5 & 6 & 7 & \\
\hline \multirow[t]{2}{*}{1} & Needle penetration depth, & 75 & 54 & 52 & 53 & 50 & 52 & 54 & 76 \\
\hline & $\begin{array}{c}0.1 \mathrm{~mm}: \text { at } 25^{\circ} \mathrm{C} \text { at } 0^{\circ} \mathrm{C}, \\
\text { not less }\end{array}$ & 22 & 18 & 16 & 14 & 19 & 15 & 16 & 22 \\
\hline 2 & $\begin{array}{l}\text { The softening temperature of } \\
\text { the ring and ball, }{ }^{\circ} \mathrm{C}\end{array}$ & 48 & 50 & 54 & 55 & 56 & 54 & 55 & 54 \\
\hline 3 & Fragility temperature, ${ }^{\circ} \mathrm{C}$ & -20 & -13 & -9 & -12 & -10 & -13 & -11 & -20 \\
\hline \multirow[t]{2}{*}{4} & $\begin{array}{l}\text { Elongation, cm: } \\
\text { at } 25^{\circ} \mathrm{C}\end{array}$ & 65 & 65 & 70 & 80 & 78 & 58 & 60 & 25 \\
\hline & at $0{ }^{\circ} \mathrm{C}$ & 32 & 35 & 28 & 44 & 48 & 56 & 54 & 11 \\
\hline 5 & Elasticity & 55 & 59 & 63 & 67 & 66 & 63 & 64 & 70 \\
\hline
\end{tabular}

\section{CONCLUSION}

The receipt of binder modified with additives based on waste rubber is developed. It was proved that the modification of rubber crumb by vermiculite increases the running ability of rubber crumb.

The structuring of bitumen provides an increase in the density of the mixture, an increase in the coefficient of internal friction, an increase in resistance to shear, shock loads, compressive strength and a decrease in brittleness.

Modified rubber crumb allows increasing the quality of bitumen binders, increasing the durability of the pavements, as well as utilize large-tonnage waste rubber products.

\section{ACKNOWLEDGEMENT}

The research was performed at M. Auezov South Kazakhstan State University in the department of oil processing and petrochemistry.

1. V. Galdina, Modified bitumen, Omsk, p.22(2009).

2. B. Pecheny, Bitumens and Bitumen Compositions, Chemistry, Moscow, p.119(2010).

3. K. Syrmanova, A. Agabekova, Z. Kaldybekova, A. Kovaleva, Y. Botashev, Rasayan Journal of Chemistry, 13(4), 2099(2020), DOI:10.31788/RJC.2020.1345897

4. A. Rudensky, Roads of Russia of the XXI Century, 5, 62(2004).

5. K. Syrmanova, Zh. Alipbekova, E. Botashev, Z., Kaldybekova, Proceedings of the International Scientific-practical Conference: Actual Problems of the Petrochemical Complex of Russian Federation, 1(5), 87(2019).

6. G. Mamytbekov, S. Kozhabekov, S. Aidarova. Physical-chemical Mechanics and Rheology of Oil Disperse Systems, Mektep, Almaty, p.89,192(2009).

7. O. Babak, Road Equipment and Technologies, 5, 72(2001).

8. K. Syrmanova, T. Rivkina, Commodity Petroleum Products, Alem, Shymkent, p.191(2016).

9. B. Tarasevich, Fundamentals of Fourier Transform IR Spectroscopy, Sample of Preparation in IR Spectroscopy, Moscow, Russian Federation, p.22,105(2012).

10. M. De Araujo Medeiros, D.L. de Oliveira, M.T.C. Sansiviero, M.H. Araujo R.M. Lago, Sorbents and Their Using, 85, 452(2010).

11. K. Syrmanova, Zh. Kaldybekova, Polyfunctional sorbents, Monograph, Shymkent, p.168(2012).

[RJC-6109/2020] 